\title{
How can river-estuarine planktonic copepods survive river floods?
}

Hiroshi Ueda ${ }^{1}$, Ayumi Terao ${ }^{1}$, Masaru Tanaka ${ }^{2}$, Manabu Hibino ${ }^{2 \dagger}$ and Md. Shahidul Islam ${ }^{2}$

${ }^{1}$ Center for Marine Environmental Studies, Ehime University, Bunkyo-cho 3, Matsuyama, Ehime 790-8577, Japan and ${ }^{2}$ Graduate School of Agriculture, Kyoto University, Oiwake-cho, Kitashirakawa, Sakyo-ku, Kyoto 606-8502, Japan

Running head: River-estuarine copepods survive floods

*Author to whom correspondence should be addressed. Email: hueda@sci.ehime-u.ac.jp

${ }^{\dagger}$ Present address: Aichi Fisheries Promotion Fund, Department of Sea-Farming, 1-3

Ichizenmatsu, Nakayama, Atsumi-cho, Aichi 441-3615, Japan 


\section{ABSTRACT}

Distribution of brackish-water zooplankton was surveyed in the Chikugo River estuary, Japan, at 3-hour intervals for 24 hours, including several hours when the river was heavily flooded due to rainfall and discharge from an upstream dam. The populations of the dominant copepods Pseudodiaptomus inopinus and Sinocalanus sinensis were concentrated in the mixing zone of the salt wedge before river flooding. During the period of flooding, they were almost completely swept out from the river, but examination of water trapped by a sediment grab sampler revealed that adults of $P$. inopinus were aggregated immediately above the bottom of the submerged channel outside the river mouth. After the flood, aggregations of both species appeared again in the river together with the salt wedge, and the proportion of adults in the aggregations became significantly higher than before. These results suggest that immature copepodids suffer population losses through river flooding, but that the copepods can survive such flooding by means of both behavioral and reproductive mechanisms; that is, adult copepods maintain their position on the bottom of submerged channels outside the river mouth during a river flood and replace the population loss through reproduction after the flood. Channels outside river mouths are thus regarded as important topographic refuges for river-estuarine zooplankton to survive a flood.

Key Words: copepods, estuary, river flood, submerged channel, survival 


\section{INTRODUCTION}

Some planktonic animals inhabiting the tidal reaches of rivers exhibit adaptive behaviors to maintain their position in the river against the residual tidal flow, i.e. long-term average flow. A well-documented behavior is ‘tidal vertical migration’ (Haertel \& Osterberg 1967; Cronin \& Forward 1979; Wooldridge \& Erasmus 1980; Hough \& Naylor 1991; Morgan et al. 1997; Kimmerer et al. 1998). Plankters maintain their position in the tidal reaches by shifting the population lower in the water column on the ebb tide than on the flood tide. When a river is swollen due to heavy rainfall and water flow is much faster than usual, however, indigenous river-estuarine zooplankton will be swept out to sea in spite of such maintenance mechanisms. Because there have been no reported instances of river floods causing local extinction of estuarine zooplankton, it seems that these organisms succeed in surviving such natural events. There have been no studies to learn how river-estuarine zooplankton manage to do this. Possible ways to withstand river floods are to return quickly into the tidal reaches without significant population losses, to recover the population loss through subsequent reproduction, or both. The present study provides some data to demonstrate the mechanism actually employed.

On 6-7 July 2001, we made a 24-hour plankton survey in the lower tidal reaches of the Chikugo River, Kyushu. The objective of the survey was to monitor the tide-related vertical migration of the dominant planktonic copepods. In the morning of 6 July, however, there was a heavy rain, which had begun the previous night. The water at the study site flowed seaward much faster than usual, especially for several hours from the late morning, because a dam $23 \mathrm{~km}$ up the river released water by fully opening its water gate at 9:10. We completed the survey despite the severe field conditions, but we failed to take adequate data for showing tidal vertical 
migration because we could collect only a small number of copepods in the tidal reaches during the period of river flooding. Nonetheless, we could observe that copepods once swept out from the tidal reaches returned quickly after the episode of flooding. This paper describes the phenomenon and presents an answer to the question of how they can do it.

\section{METHODS}

The study site was the tidal reaches of the Chikugo River and the submerged channel outside the river mouth (Fig. 1). The bottom of the channel was about $3 \mathrm{~m}$ deeper than the surrounding intertidal mudflat. The dominant zooplankton species at the site in summer are two brackishwater calanoid copepods, Pseudodiaptomus inopinus Burckhardt and Sinocalanus sinensis (Poppe), which are known to occur usually in water with a salinity of less than 20 psu (Hibino 2000). Nine sets of zooplankton samplings were made at about 3-hour intervals from the flood tide in the morning of 6 July 2001 to the same tide of the following day. The high tides were at 9:39 and 22:39 on 6 July and the low tides were at 16:02 on 6 July and 4:36 on 7 July. The sunset on 6 July was at 19:32 and the sunrise was at 5:16 on 7 July.

In each set, zooplankton was taken at 3 to 5 consecutive stations out of a total of 6 stations located along the river axis. Samplings were made in ascending order of station number except for the fifth set, in which samplings were done from St. 5 to St. 1, and the time to start each sampling set is presented in Fig. 2. At each station, water samples were taken from the surface and about 0.5 to $1 \mathrm{~m}$ above the bottom using a self-closing trap-type water sampler designed by Ueda \& Yoshimura (1992), with the volume of the sampler enlarged to $12 \mathrm{~L}$. Middepth water samples also were taken at one or two stations in the first three sampling sets. 
The boat was left to drift during sampling at each station, without driving it against the water flow or anchoring it, in order to be able to deploy the sampler vertically in the water column. Copepods in $10 \mathrm{~L}$ of the water were collected by sieving through a $200-\mu \mathrm{m}$ mesh cloth and fixing with $2 \%$ formalin solution on board the boat. Salinity, temperature, and turbidity were measured simultaneously with the water sampling at depth intervals of $2 \mathrm{~m}$ at 4 or 5 consecutive stations using a portable water quality meter (DKK-TOA Corp., Model WQC-22A). The time required to complete one sampling set was approximately 1.0-1.5 hours, most of which was spent in moving between the stations.

In addition to the samples collected by the water sampler, the water immediately above the bottom was collected together with bottom mud at three different sites, near St. 2 at 14:30 (between the third and fourth sets), St. 6 at 16:30 (just after the fourth set), and on the mudflat near St. 6 at 18:40 (after sampling at St. 5 in the fifth set), using an Ekman grab sampler $\left(225 \mathrm{~cm}^{2}\right.$ in mouth area). To collect copepods, the water in the grab was sieved through a $200-\mu m$ mesh cloth on board the boat and the mud was sieved through the same cloth by adding water in the laboratory.

Developmental stages of $P$. inopinus and $S$. sinensis copepods were distinguished and all copepods collected were counted under a microscope.

\section{RESULTS}

\section{Environmental conditions of the site}

In the first sampling set in the morning of 6 July, the river was already swollen due to rainfall since the previous evening, but riverward water flow on the flood tide was still weakly observed. 
A distinct salt wedge was found in the river in the first and second sets (Fig. 2). The wedge did not move riverward from the first set on the flood tide to the second set on the high tide, indicating the rainfall had already strongly affected on the river flow at the second set. The water flow became much faster seaward a short time after the second set, which was apparently due to release of water from a dam upstream. The water in the entire study area was completely fresh in the third and fourth sets; under the usual conditions, a freshwater never reaches St. 4 even on a low tide (Shirota and Tanaka 1981). Henceforth we refer to the time of the third and fourth sets as 'the period of river flooding'. In the evening, when the rain had almost stopped, a seaward surface-water flow was still observable in spite of the flood tide, but a salt wedge had appeared again in the channel outside the river mouth. This indicates that the saline bottom water was flowing as a countercurrent to the seaward surface-water flow. At the nighttime of 6 July, the surface water was still fresh even in the channel outside the river mouth, but the saline bottom water reached to a point between St. 2 and St. 3 in the river. The riverward tip of the mixing zone of the salt wedge moved about $7 \mathrm{~km}$ seaward, from St. 2 at high tide to St. 5 in the channel outside the river mouth at low tide at night. It returned into the river on the flood tide the next morning. The salt wedges at the fifth and ninth sets on the flooding tide lay much seaward than that at the first set on the same tide, This indicates that the effect of the river flood still considerably remained even at the ninth sampling set.

Water temperature before the period of river flooding ranged from $25.8^{\circ} \mathrm{C}$ to $27.8^{\circ} \mathrm{C}$ and was higher in the bottom layer of the seaward stations. During the river flooding, the water was significantly cooler $\left(22.5-24.0^{\circ} \mathrm{C}\right)$ and no vertical difference was observed in either temperature or salinity, indicating strong turbulence caused by swift downward flow. Starting with the sixth 
sampling set on the high tide, the temperature rose to $24-25^{\circ} \mathrm{C}$ in the bottom layer in the channel outside the river mouth despite the nighttime cooling of the surface water.

Turbidity greatly varied during the course of the survey (Fig. 3). The turbid bottom water (>200 ppm) at the riverward stations in the second sampling set is considered to have resulted from resuspension of bottom mud due to the swift water flow. The water in the river was extremely turbid ( $>800 \mathrm{ppm}$ ) during the period of river flooding, but less turbid water ( $<400$ ppm) remained in the bottom layer of the channel outside the river mouth on the ebb tide. Turbidity of the mid- and surface water decreased gradually to $<400 \mathrm{ppm}$ on the high tide at night. Highly turbid freshwater remained near the salt wedge until the low tide of the next early morning. The water on the flood tide of 7 July was clearer than that at the preceding low tide but still more turbid than that on the same tide before the period of river flooding, indicating that the effect of river flooding persisted to the following day.

\section{Copepod distribution}

Pseudodiaptomus inopinus and Sinocalanus sinensis were equally abundant in the samples collected by the water sampler and their distributions in the estuary were similar to each other (Figs. 4 and 5). In the first sampling set, when both species were observed to aggregate in the mid-layer at St. 3 in the mixing zone of the salt wedge, a difference in distribution was seen between them at the more riverward stations (Sts. 1 and 2) with a salinity of less than 0.1 psu. There, S. sinensis was absent but $P$. inopinus was present at a density of $1.1 \mathrm{~L}^{-1}$. In the second set, they were again aggregated in the bottom layer of St. 3, with the highest abundances observed in the present survey (23.6 $\mathrm{L}^{-1}$ for P. inopinus and $16.3 \mathrm{~L}^{-1}$ for $S$. sinensis). During the period of river flooding, no $P$. inopinus were found in the samples collected by the water sampler, and only 
$1\left(0.1 \mathrm{~L}^{-1}\right)$ adult or late copepodid of $S$. sinensis appeared in each of the three water samples from the bottom layer at St. 2 on the ebb and low tides and the mid-layer at St. 3 on the low tide. A small number (0.4-1.1 $\left.\mathrm{L}^{-1}\right)$ of copepods of both species occurred in the saline bottom-water from the flood tide in the evening through the ebb tide at midnight. On the next low tide, aggregations of both species were formed at the tip of the salt wedge in the channel outside the river mouth; their densities were comparable to those observed in the first sampling set. These aggregations moved to the river mouth with the salt wedge on the flood tide the next morning. The proportion of adults in these aggregations were significantly higher (58\% in P. inopinus and $61 \%$ in $S$. sinensis) than those in the first sampling set (3\% and 35\%, respectively; $p<0.001$ for both species, test of the difference of the population ratios). The sex ratios of adult copepods in these aggregations were not extremely biased (female ratios 0.39-0.62 in P. inopinus and 0.43-0.61 in P. inopinus).

Among the samples taken by the sediment grab sampler, the sample collected in the channel outside the river mouth (St.6) at 16:30, during the period of river flooding, contained 34 specimens of $P$. inopinus. These were all adult copepods and all were found in the trapped water except for one specimen in the mud sample. The volume of the trapped water was not measured but was clearly less than $1.5 \mathrm{~L}$ because the mud sample occupied more than half the capacity (3.3 L) of the sampler; therefore the density of the copepods in the trapped water was comparable to that in aggregations observed before the river flooding. One adult specimen of $P$. inopinus was also discovered in the trapped water of the sample taken near St. 2 at 14:30, but the sample from the mudflat near St. 6 at 18:40 on the flood tide contained no copepods. No specimen of $S$. sinensis was found in any grab sample. 


\section{DISCUSSION}

As far as we know, there have been no studies on the mechanism by which river-estuarine zooplankton survive river floods. One reason for the lack of such studies may be practical difficulties in monitoring zooplankton distribution in a flooded river. Especially, plankton sampling using a small boat in a rapidly flowing river is very risky. The original aim of our investigation was not to study the survival mechanism of the dominant copepods during floods, but to demonstrate a vertical migration and tidal current-related retention mechanism under normal conditions of the river estuary, as have been done by many other authors (e.g., Kimmerer et al. 1998). Accordingly the sampling scheme was not necessarily adequate to document all details of their survival mechanism. A major fault in the scheme was the location of the sampling stations, which did not cover the whole range of distribution of the object copepods Pseudodiaptomus inopinus and Sinocalanus sinensis; their populations were distributed much more seaward than we expected based on our previous studies in this estuary (Hibino 2000; Hibino et al. 1999).

The present study is, however, providing important hints as to how they can survive river floods. Water sampling revealed that dense populations of both species were restricted to a single station situated in a mixing zone with a salinity of 5-20 psu, in contrast to much lower densities or absence of the copepods at the neighboring stations. The major part of the population was thus concentrated in the mixing zone of the salt wedge. During the period of river flooding, the water was fresh even at St. 6, the seaward end of the channel outside the river mouth, and no or very few copepods were captured in the water sampler. Instead, a number of $P$. inopinus were discovered in the water trapped by the sediment grab sampler at St. 6. These facts 
indicate that the flood almost completely swept the populations of both copepods out of the river, but part of the $P$. inopinus population remained in an aggregation on the bottom of the submerged channel. This aggregation must have been confined to a very thin layer on the bottom since the copepods were absent in the bottom water sample taken 0.5-1 $\mathrm{m}$ above the bottom at the same site just before the grab sample. Although the salinity in the bottom layer (about $1 \mathrm{~m}$ above the bottom) at St. 6 in the fourth sampling set was zero, the aggregation of $P$. inopinus in the grab sampler suggests that saline water remained on the bed of the channel during the period of river flooding.

In general, saline water in the mixing zone of a river estuary would tend to be retained more on the bottom of channels outside the river mouth than in the bed of the river proper. This is because freshwater in the surface layer above the submerged deep channels would flow more slowly due to its spreading horizontally and in consequence vertical mixing of water would be weaker there than in the river. Weaker turbulence in the channel is also suggested by the fact that, on the ebb tide during the river flood, the water was less turbid on the bottom of the submerged channel outside than in the river itself. In addition, the freshwater covering the channel may keep copepods on the bed of the channel by preventing their upward migration (Grindley 1964). Copepods retained in the channel outside could return successfully to the river on the next flood tide. Thus, submerged channels outside a river mouth are regarded as important topographic refuges that allow river-estuarine zooplankton to survive floods.

We did not discover any aggregation of $S$. sinensis during the period of river flooding. This species showed almost the same distribution pattern as $P$. inopinus in the estuary, but its distribution in the first sampling set somewhat differed from $P$. inopinus, that is, $S$. sinensis was absent at St. 1 and St. 2 where $P$. inopinus was present. This suggests that $P$. inopinus is more 
tolerant of fresh- or extremely low saline water than $S$. sinensis and may account for the absence of $S$. sinensis at the point on the channel bed where $P$. inopinus aggregated.

To evaluate population losses caused by river flooding, it is essential to consider organisms' capacity for surviving such floods. The present results show that the populations of $P$. inopinus and S. sinensis in the Chikugo River estuary are usually concentrated in the mixing zone of the salt wedge. Copepod densities in the samples collected from these aggregations, however, do not necessarily provide good estimates of their population losses, because the densities no doubt vary greatly depending on the degree of concentration and the position in the aggregation. Instead, the stage composition of the copepod population could provide better information because this may not vary much with the degree of concentration or position in the aggregation. The aggregated copepods on the channel bed outside the river mouth during the period of river flooding were exclusively adults, indicating that adult copepods could maintain their position more successfully in the channel than immature copepodids, and therefore that the latter must suffer greater losses than the former. The proportion of immature copepodids in aggregations of $P$. inopinus dropped from $86 \%$ in the second sampling set to $42 \%$ in the ninth set, and those of $S$. sinensis were from $63 \%$ to $39 \%$. Assuming that adult copepods did not suffer population losses and the stage compositions were uniform in their aggregations, $76 \%$ and $94 \%$ losses of immature copepodids by $P$. inopinus and $S$. sinensis, respectively, are calculated from the deceases in the proportion of immature copepodids. These values imply that population losses due to river flooding were significant at least for immature copepodids, and accordingly, that the copepods would be forced to make up for these losses by reproduction after the flood.

In conclusion, the present study indicates that the river-estuarine copepods in the Chikugo River estuary survive river floods by both behavioral and reproductive mechanisms; adult 
copepods maintain their position on the bottom of submerged channels outside the river mouth during river floods, and they replace losses of immature copepodids through reproduction after the flood.

\section{ACNOWLEDGEMENTS}

We are grateful to Drs F.D. Ferrari, Smithsonian Institution, and M.J. Grygier, Lake Biwa Museum, for critical reading and improving of the manuscript, Messrs. K. Sakemi and S. Koga for driving the boat, and students of Kyoto University and Ehime University for field assistance. This work was supported by a grant of the Nissei Foundation to MT.

\section{REFERENCES}

Cronin T. W. \& Forward R. B. Jr. (1979) Tidal vertical migrations: an endogenous rhythm in estuarine crab larvae. Science 205: 1020-1022.

Grindley J. R. (1964) Effects of low-salinity water on the vertical migration of estuarine plankton. Nature 203: 781-782.

Haertel L. \& Osterberg C. (1967) Ecology of zooplankton, benthos and fishes in the Columbia River estuary. Ecology 48: 459-472.

Hibino M. (2000) [Early life history of Japanese temperate bass in the inner part of Ariake Sound: comparison between a surf zone and a river estuary]. MS thesis, Kyoto University, Kyoto, Japan. (In Japanese.)

Hibino M., Ueda H. \& Tanaka M. (1999) Feeding habits of Japanese temperate bass and copepod 
community in the Chikugo River estuary, Ariake Sea, Japan. Nippon Suisan Gakkaishi 65: 1062-1068. (in Japanese with English abstract.)

Hough A. R. \& Naylor E. (1991) Field studies on retention of the planktonic copepod Eurytemora affinis in a mixed estuary. Marine Ecology Progress Series 76: 115-122.

Kimmerer W. J., Burau J. R. \& Bennett W. A. (1998) Tidally oriented vertical migration and position maintenance of zooplankton in a temperate estuary. Limnology and Oceanography 43: 1697-1709.

Morgan C. A., Cordel J. R. \& Simenstad C. A. (1997) Sink or swim? Copepod population maintenance in the Columbia River estuarine turbidity-maxima region. Marine Biology 129: 309-317.

Shirota A. \& Tanaka K. (1981) Studies on the suspended matter in the Ariake Bay - I. Transportation of the clay floc-suspension from the Chikugo River to the estuary. Bulletin of the Seikai Regional Fisheries Research Laboratory 56: 27-38. (in Japanese with English abstract.)

Ueda H. \& Yoshimura M. (1992) Improved Patalas' self-closing water sampler - the easiest middepth use. Bulletin of Plankton Society of Japan 38: 149-150.

Wooldridge, T. \& Erasmus, T. (1980) Utilization of tidal currents by estuarine zooplankton. Estuarine, Coastal and Shelf Science 11: 107-114. 
Figure legends

Fig. 1. Map of the Chikugo River estuary with sampling stations. Broken lines show the extent of the intertidal mudflat outside the river mouth.

Fig. 2. Salinity profiles in the Chikugo River estuary. Small circles indicate the sampling depths at each station. The depth of the bottom at each station varied depending on the tide and the position of the boat in the river when the measurement was done. The time in parentheses is the starting time for sampling at each tidal stage.

Fig. 3. Turbidity profiles in the Chikugo River estuary. See Fig. 2 for further explanation.

Fig. 4. Distribution of Pseudodiaptomus inopinus in the Chikugo River estuary before and after the period of river flooding on 6 July 2001. The letters 'S', 'M', and 'B' represent surface, middepth, and bottom layers, respectively, which are shown in Fig. 2. The length of each horizontal bar represents the cumulative number of copepods per liter: early copepodids (CICIII, white bar), late copepodids (CIV-CV, grey bar), and adults (black bar).

Fig. 5. Distribution of Sinocalanus sinensis in the Chikugo River estuary before and after the period of river flooding on 6 July 2001. See Fig. 4 for further explanation. 


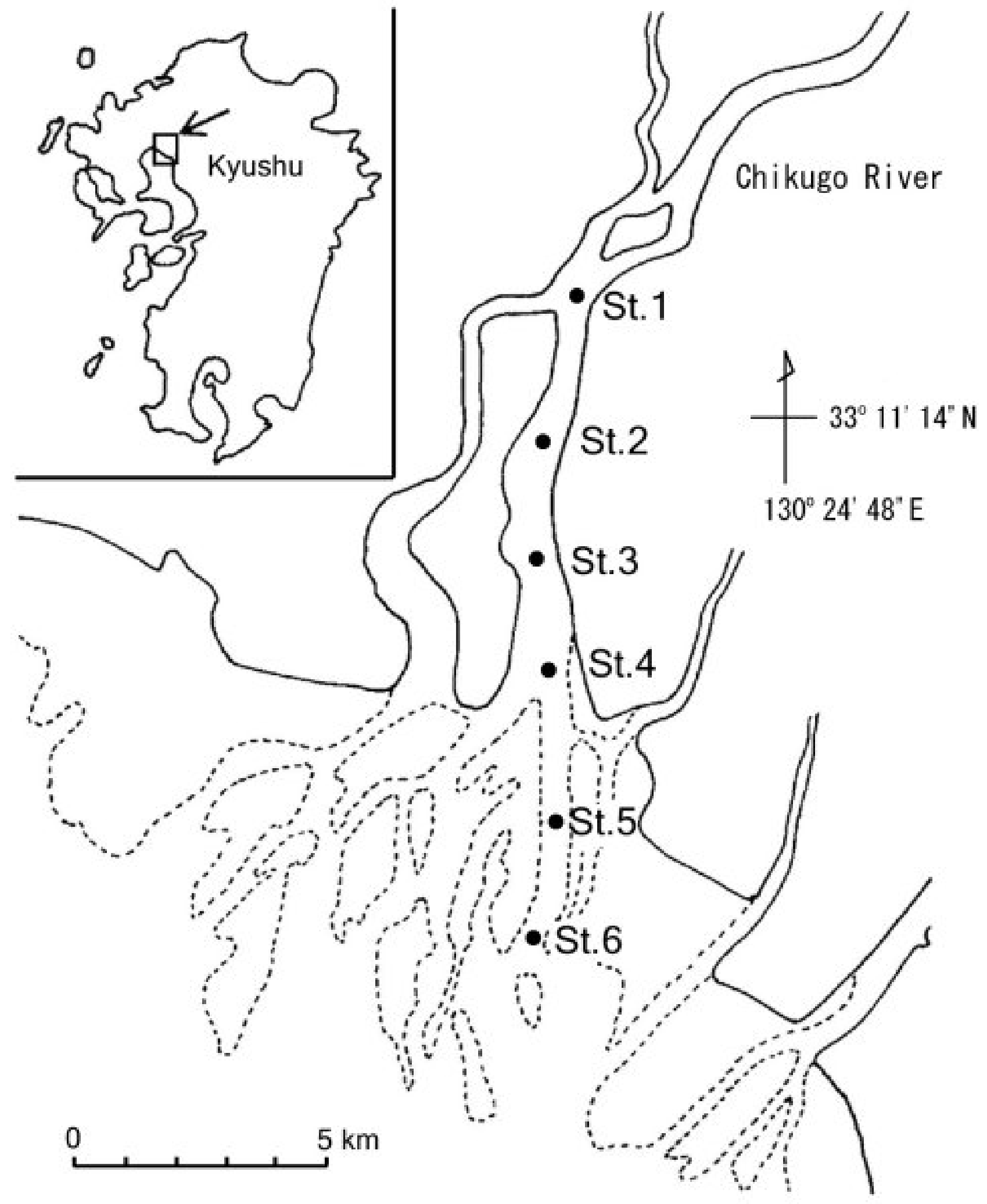


6 July 2001

I. Flood tide

(07:00)

II. High tide (09:31)

III. Ebb tide

(12:47)

IV. Low tide

(15:30)

V. Flood tide

(18:30)

VI. High tide

(22:09)

7 July 2001

VII. Ebb tide

(01:00)

VIII. Low tide (04:00)

IX. Flood tide (06:59)
Channel

outside river

\section{$\begin{array}{llllll}\text { St.1 } & \text { St. } 2 & \text { St. } 3 & \text { St.4 } & \text { St.5 } & \text { St.6 }\end{array}$}
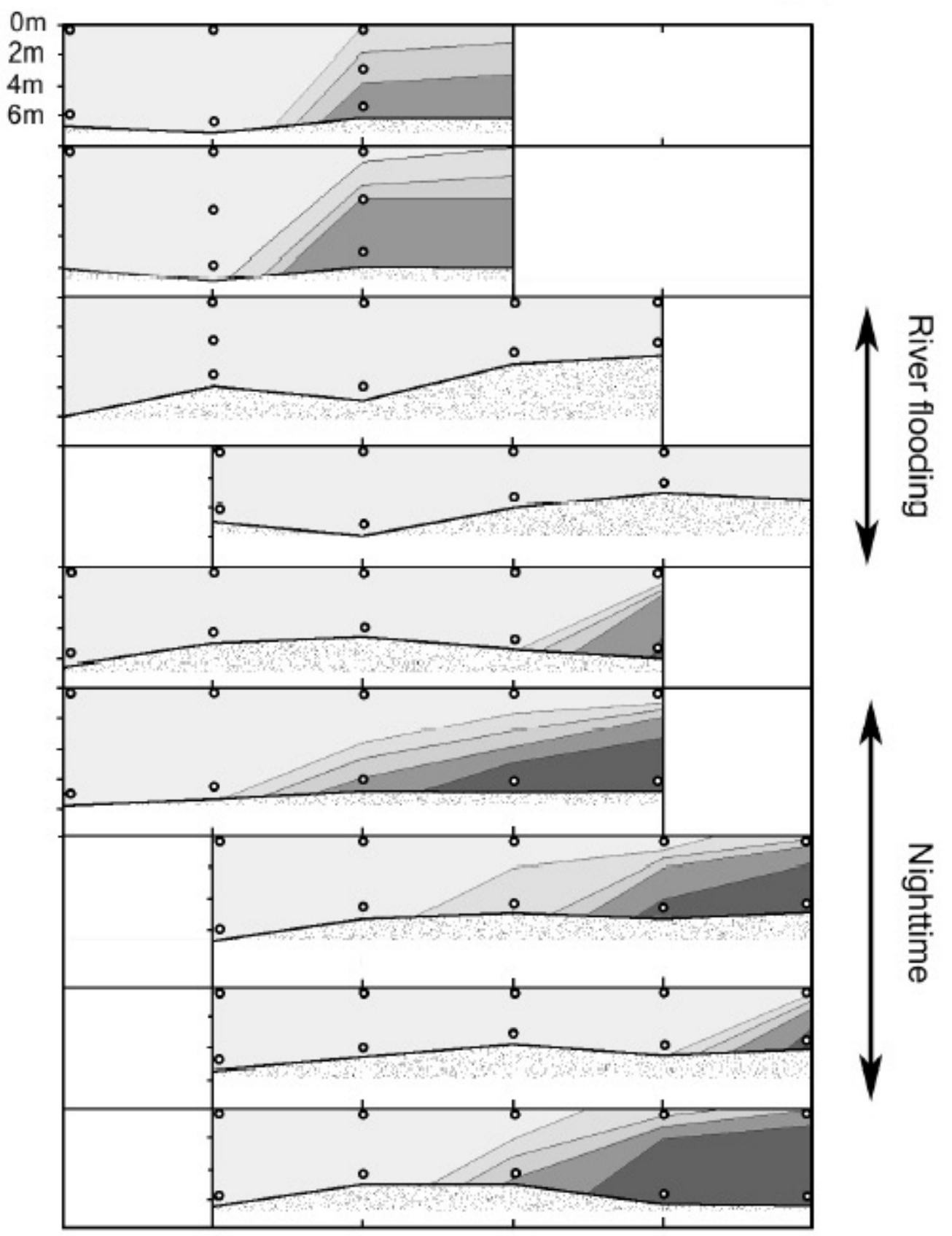

$\square<1, \square<5, \quad \square<10, \square<20, \square>20$

Salinity (p.s.u.) 
Channel

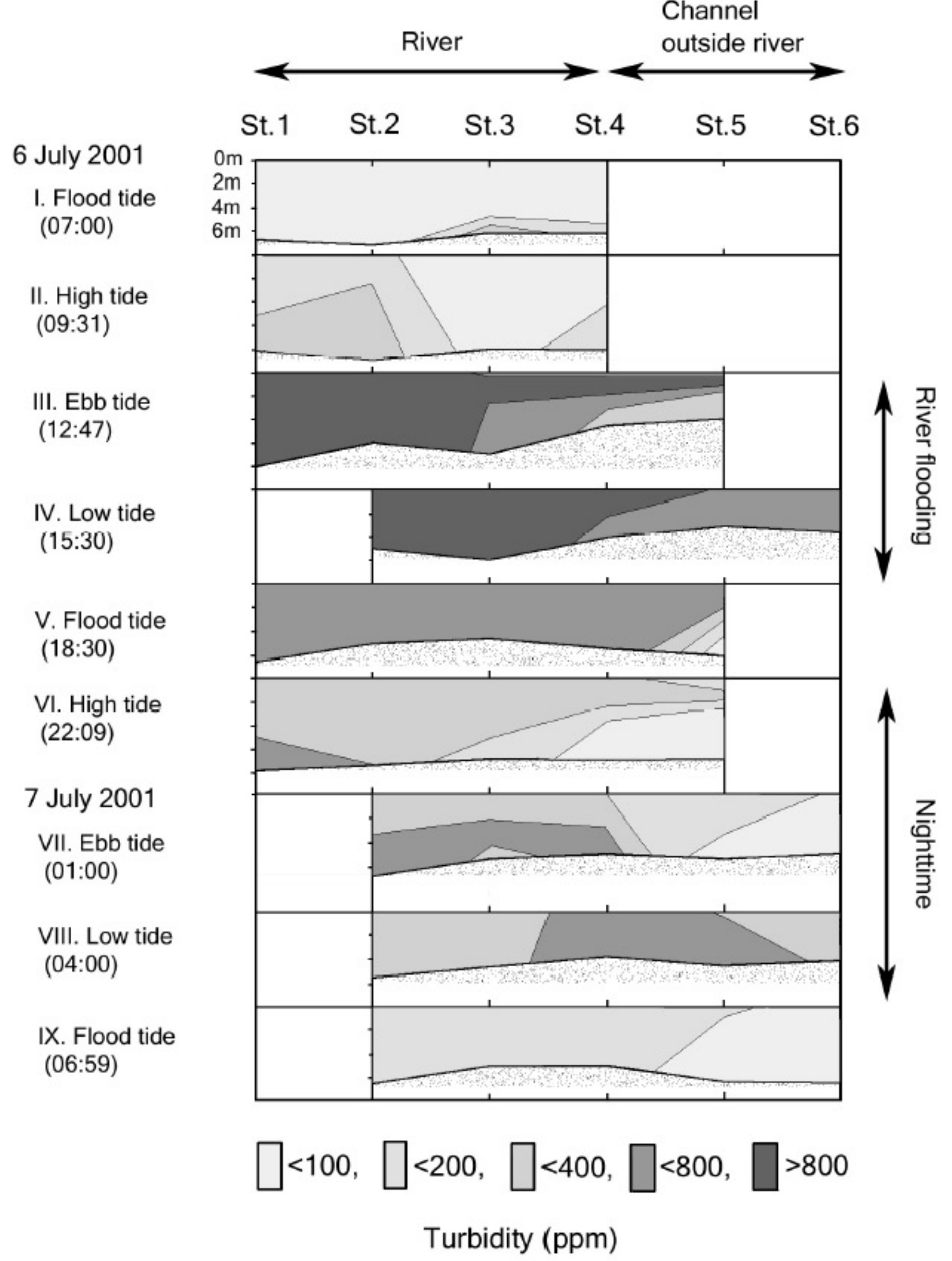




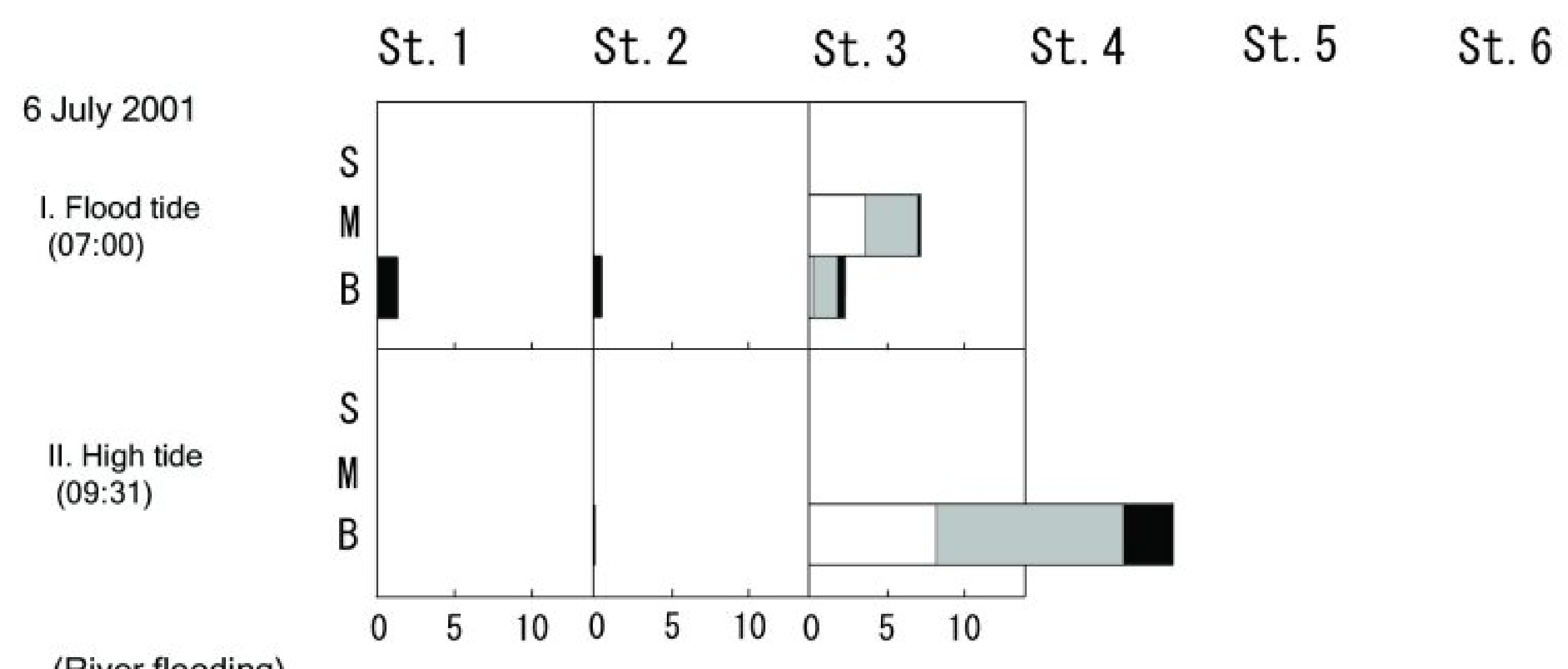

(River flooding)

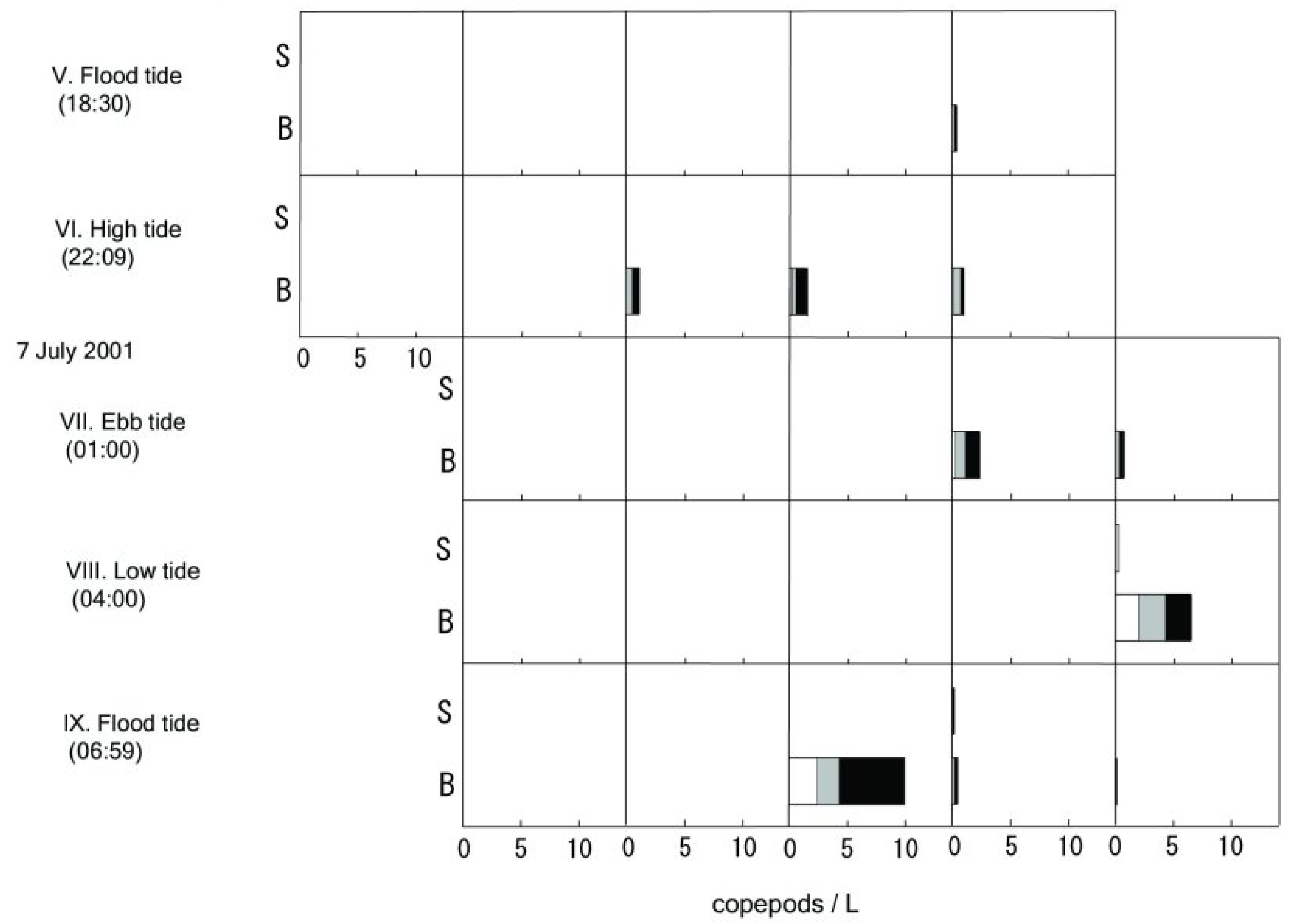


$\begin{array}{llllll}\text { St. } 1 & \text { St. } 2 & \text { St. } 3 & \text { St. } 4 & \text { St. } 5 & \text { St. } 6\end{array}$

6 July 2001

I. Flood tide

(07:00)

II. High tide

(09:31)

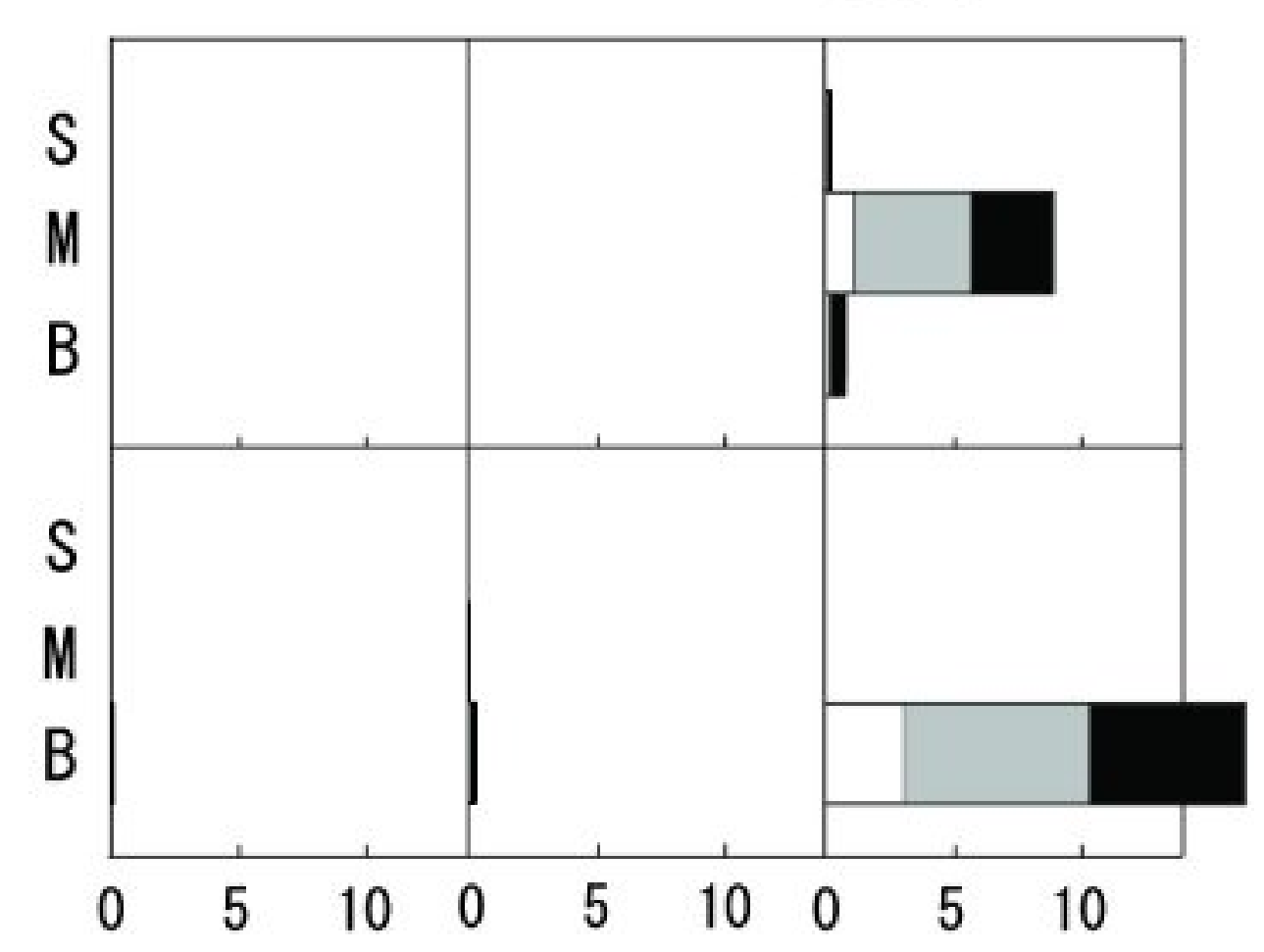

(River flooding)

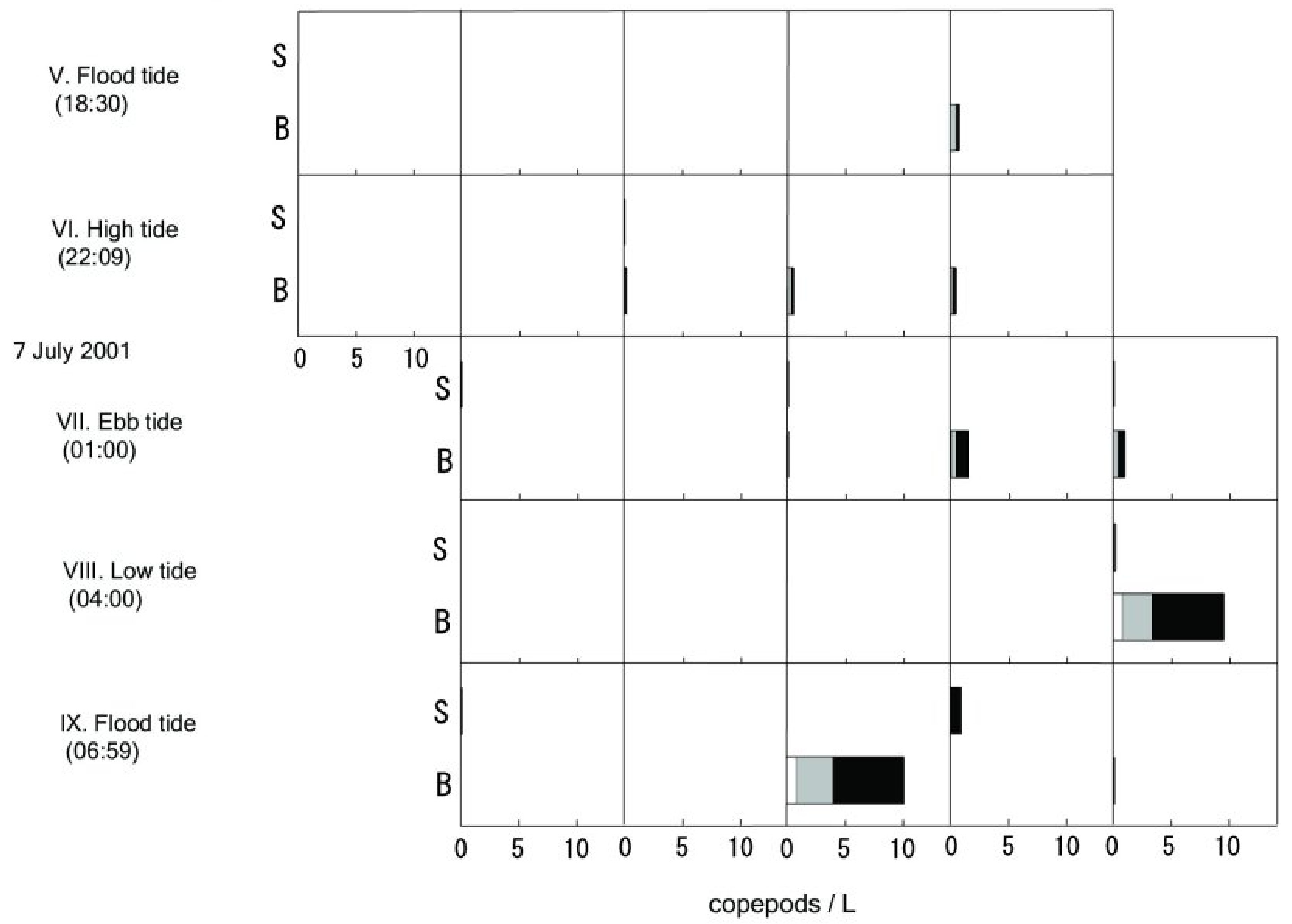

